RU Заимствование как источник коллоквиализации современного немецкого языка

\author{
Белякова О. П., Нефедова Л. А.
}

\begin{abstract}
Аннотация. Цель исследования - выявить роль заимствования в коллоквиализации немецкого языка конца XX - начала XXI в. В статье рассматриваются причины заимствования коллоквиализмов; коллоквиализмы-заимствования анализируются в диафазическом, диастратическом и тематическом аспектах. Научная новизна исследования заключается в многостороннем и комплексном подходе к интерпретации современных заимствований с учетом языковой вариативности и тематической соотнесенности языковых единиц. В результате исследования установлено, что заимствованная лексика нехарактерна для современной немецкой разговорной речи и представляет собой в основном англоязычные жаргонизмы, а также гибридные образования из автохтонных и заимствованных элементов.
\end{abstract}

\title{
EN Borrowing as Colloqualization Source in the Modern German Language
}

\author{
Belyakova O. P., Nefedova L. A.
}

\begin{abstract}
The research objective is as follows: to identify borrowings role in colloqualization of the German language of the end of the XX - the beginning of the XXI century. The article examines causes of colloquialisms borrowing; the borrowed colloquialisms are analyzed taking into account diaphasic, diastratic and thematic aspects. Scientific originality of the paper involves the comprehensive approach to studying newly appeared borrowings taking into account language variability and thematic affiliation of linguistic units. The findings allow concluding that the borrowed vocabulary is scarcely represented in the German colloquial speech and basically includes the English jargonisms and hybrids containing autochthonic and borrowed elements.
\end{abstract}

\section{Введение}

Определенный пласт лексических единиц в каждом живом языке образуют заимствования, которые в большинстве случаев обозначают новые понятия и явления, перенятые одной культурой из другой, и представляют собой в последнее время в основном терминологию сфер экономики и информационных технологий. Вместе с тем заимствования не чужды и разговорной речи.

Актуальность темы исследования обусловлена тем, что заимствованная лексика проникает также в сферу неофициального общения, выступая источником коллоквиализации языка, т.е. наполнения его лексическими единицами, характерными для разговорной речи. Однако эта проблема не затрагивалась в работах, посвященных вопросам заимствования на современном материале [6].

Для достижения цели исследования были сформулированы следующие задачи:

- выявить коллоквиализмы-заимствования в немецком языке конца XX - начала XXI в. и описать причины их заимствования;

- проанализировать коллоквиализмы-заимствования в диафазическом (стилистическом), диастратическом (социальном) и тематическом аспектах;

- разграничить понятия «коллоквиализм», «жаргонизм», «молодежный жаргонизм» и «субкультурная лексика».

В статье применяются следующие методы исследования: метод сплошной выборки языковых единиц, метод лингвистического наблюдения и описания, метод анализа словарных дефиниций.

Материалом для исследования послужила лексика немецкого языка с регистровыми пометами разговорное; разг.-шутливое; разг.-насмешливое; шутливое; фамильярное; жаргон; молод. жаргон и субкультурное, которая была отобрана из онлайн-версии Словаря неологизмов “Neologismenwörterbuch”, представленного на вебпортале OWID Института немецкого языка им. Лейбница в Мангейме [19]; словаря “DWDS-Themenglossar zur 
COVID-19-Pandemie”, посвященного теме пандемии коронавируса [13]; а также из Немецко-русского словаря разговорной лексики В. Д. Девкина [3].

Теоретической базой данного исследования послужили, прежде всего, работы профессора В. Д. Девкина [1-3], в центре внимания которого находились лексические и грамматические особенности немецкой разговорной речи, посредством которой осуществляется непринужденное межличностное общение. Методологический ориентир исследований - фундаментальный труд ученого «Немецкая разговорная речь: синтаксис и лексика» [2].

Исследование базируется также на работах учеников профессора В. Д. Девкина, исследовавших проблемы заимствования в немецкой разговорной речи. Коллоквиализмам-заимствованиям была посвящена кандидатская диссертация 1974 г. Ю. Г. Коротких [5]. В кандидатской диссертации 1999 г. Е. А. Никитиной о наречияхколлоквиализмах рассматривались также заимствованные разговорные наречия [8]. K теме возникновения коллоквиализмов на основе терминологической лексики, представляющей собой в основном латинизмы и грецизмы, т.е. заимствованную лексику, обращалась в своей докторской диссертации 2005 г. В. А. Собянина [9]. На коллоквиализмы, состоящие из несопоставимых немецких и заимствованных, противоречащих языковой норме, элементов, обращалось внимание в докторской диссертации 2003 г. Л. А. Нефедовой [7].

Практическая значимость исследования заключается в том, что его результаты могут быть использованы в курсе лексикологии и практике преподавания немецкого языка на факультетах иностранных языков в вузах.

\section{Понятие «коллоквиализм». Разговорная лексика и заимствование}

Под обиходно-разговорным языком, или разговорной речью (нем. Umgangssprache), понимают язык, который используется в повседневной жизни (дома, в общении с друзьями), занимая промежуточное положение между диалектом и литературным, или стандартным, языком. Понятие «разговорная речь» также имеет значение «небрежная, сниженная и даже грубая манера речи». В. Д. Девкин подчёркивал: «Раскованность, непринужденность, своего рода “безгалстучность” обиходной речи накладывает свой отпечаток на оформление высказываний и, не в последнюю очередь, на выбор слов» [3, с. 12]. Ученый определял разговорную речь следующим образом: «разговорность» - это традиционное, весьма условное и собирательное название того, что противопоставлено идеально правильному, непогрешимому образцово-показательному культурному стандарту [Там же].

Разговорную лексику понимают как слова, употребляющиеся в непринужденной беседе. Термин «коллоквиализм» (лат. colloqui - разговаривать) - синоним понятия «разговорная лексика». В узком смысле коллоквиализмы представляют собой лексику общеразговорного языка, что отличает их от жаргонизмов и сленгизмов, сфера употребления которых ограниченна.

У. Аммон писал, что коллоквиализмы можно рассматривать как языковые единицы, выражающие нормы разговорного языка (т.е. определенный стилистический пласт литературного языка) или нестандартные/нелитературные языковые формы [11]. К.-Г. Бест отмечал, что лексика разговорной речи, в отличие от лексики стандартного языка, очень молода: “Der Wortschatz der Umgangssprache ist also verglichen mit dem der Standardsprache sehr jung” [12, S. 35].

Коллоквиализмы широко используются в повседневном общении. В. Д. Девкин указывал на следующие основания для этого: «Если поставить вопрос, почему прибегают в общении к разговорной, а не к нейтральной лексике, то оснований для этого несколько: а) установка на создание простой, свободной, неофициальной, нескованной атмосферы общения (разговорные слова дают почувствовать себя как дома в шлёпанцах), б) стремление выразиться попривычнее, попроще, попонятнее, соблюсти неписаную конвенцию - норму повседневного разговора, в) бездумное, некритичное следование речевым образцам родной среды, господствующей моде, желание быть таким, как все, г) в то же время желание выразиться пооригинальнее, помоднее, покрасивее, посмешнее, поозорнее. Противоборствуют при этом императивность господствующего стереотипа и творческого начала обновления и совершенствования языковых средств» [1, с. 105].

Можно предположить, что заимствованные слова в разговорной речи являются неуместными. Выражать свои мысли просто и доходчиво можно с помощью слов родного языка. В разговорной речи мы не задумываемся о выборе слов и поэтому «следуем речевым образцам родной среды», употребляя привычные и знакомые нам слова, а не заимствования, потому что находимся у себя дома «в шлёпанцах». К заимствованиям мы обращаемся, когда хотим выразиться «пооригинальнее, помоднее».

Обратившись к Немецко-русскому словарю разговорной лексики В. Д. Девкина, можно увидеть, что коллоквиализмы-заимствования нехарактерны для немецкой разговорной речи. Большинство заимствований представляют собой слова, которые давно вошли в повседневный обиход и ассимилировались в обиходноразговорную речь. Несмотря на их иноязычное происхождение, они воспринимаются как «свои», привычные.

Заимствования встречаются среди безоценочной разговорной лексики, слов «без семантического осложнения, лишённых оценочности и экспрессии, денотативно семантически очень близких нейтральным, однако всё же маркируемых словарями как характерные для неофициального общения, как разговорные» [Там же, с. 108]. Заимствования являются также оценочными словами разговорной речи, чаще с отрицательной оценкой, и разговорно-окрашенными вторичными номинациями (разговорная метафора).

В разговорном словообразовании иноязычные суффиксы, например латинский суффикс -itis, придают словам с немецкими основами псевдонаучное звучание: Rederitis - 'осуждаемая болтливость', Schenkeritis ‘помешанность на подарках, особенно на Рождество'. 


\section{Причины заимствования новых коллоквиализмов}

Новая заимствованная разговорная лексика отражает современную тенденцию - заимствования только из английского языка за минимальным исключением [16]. Количество отобранных слов и выражений из Словаря неологизмов, в состав которого входит около 2100 слов и словосочетаний, начиная с 90 -х годов XX в. и включая нулевые годы XXI в., составило 67 единиц (около 3\%). В этот список не вошли слова тематической группы «Компьютер и Интернет». Что касается второго десятилетия XXI в., было выявлено только три заимствованных разговорных слова.

\section{Заимствованная разговорная лексика в Словаре неологизмов}

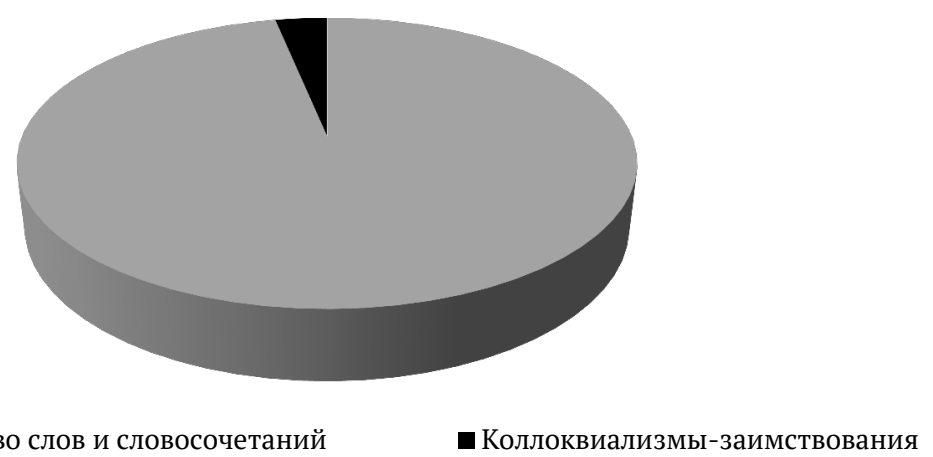

Ш Общее количество слов и словосочетаний

ш Коллоквиализмы-заимствования

Диаграмма 1. Заимствованная разговорная лексика в Словаре неологизмов

Мы выделили несколько причин, по которым в повседневном общении прибегают к заимствованной разговорной лексике.

1. Новизна, выразительность и престижность

Англицизмы придают речи новизну и выразительность, они имеют статус “vogue-words” / «модных слов». «Имиджевые» слова иноязычного происхождения, как подметил Г. Ортнер, используются для «украшательства иностранным оперением» [20, S. 236].

\section{2. Необходимость}

Здесь речь идет о том, чтобы дать наименование вещи или явлению, которые в немецком языке невербализованы. Пример слова, для которого не существует (точного, краткого или выразительного) эквивалента в собственном языке: Flipflop - ‘флип(-)флоп’, ‘вьетнамка', ‘сланец’, 'шлёпка', ‘сандалия с ремешком между большим и средним пальцами ступни’. Такие сандалии раньше носили как пляжную обувь. В США они назывались flip-flops - букв. 'шлёп-шлёп’ из-за звука, производимого при ходьбе.

\section{3. Краткость английского языка}

Следующей причиной использования заимствований в разговорной речи является краткость английских слов. Они заменяют объёмные сложные слова более лаконичными: Date - 'тот, кому назначено свидание для дальнейшего развития взаимных отношении“; теga-in - 'чрезвычайно актуальный, модный, популярный’; mega-out - ‘абсолютно неактуальный, совершенно немодный’.

\section{4. «Языковые пряности». Импульс к языковой игре}

Этот пункт можно рассматривать как один из важнейших, поскольку он наиболее близок к объяснению причины проникновения заимствований и, в частности англицизмов, в разговорный язык.

Игровое использование иноязычных элементов как средство лексических инноваций в особенности привлекательно для молодых людей. Молодежь часто создает или использует специальный вокабуляр. Английские заимствования приходят в разговорную речь часто через молодёжный лексикон [16]. Для современной молодёжи англицизмы - ценнейшие специи на кухне коммуникации.

Несложно заметить, что молодёжный язык в состоянии как заимствовать чужое, так и создавать новое. Сюда можно отнести появление в разговорной речи псевдоанглицизмов, которые не являются прямыми заимствованиями, но они образованы из заимствованных элементов. Их образование может служить для групповой сплоченности и, кроме того, является признаком оригинальности. Новые псевдоанглицизмы могут быть сопоставимы с игрой слов, привлекающей к себе внимание. Например, псевдоанглицизм DJane - 'девушка-диджей’ образован от заимствованного слова $D J$ - 'диджей, дискжокей’ путем замены буквы Ј созвучным женским именем Jane. Best Ager - жарг. ‘бестейджер/бестэйджер’, 'человек как адресат рекламы и активный потребитель рекламируемых товаров'.

Благодаря своей краткости англицизмы очень хорошо подходят для образования композитов. Так, довольно часто уже интегрированные в немецкий язык англицизмы по-новому комбинируются, чтобы образовать новые слова, например: Billigjob - 'грошовая/копеечная работа', Designerbaby - 'генетически сконструированный/смоделированный ребёнок’. Глагол containern - (англ. to dumpster dive - вытаскивать что-л. 
из мусорных баков), жарг. ‘фриганить' (доставать из мусорных контейнеров продукты питания с истекшим сроком годности в знак протеста против расточительства современного общества потребления) - имплицитный дериват от существительного Container.

Встречаются экспрессивные выражения с вкраплениями заимствованных слов, например: фразеологизм der Drops ist gelutscht (букв. леденец съеден) - ‘дело сделано’, ‘поезд ушёл', ‘что-л. уже нельзя вернуть назад, исправить’ является метафорическим переосмыслением: невозможность решить по-иному, исправить что-л. осмысляется как необратимое действие над объектом, приводящее к прекращению самого его существования. Другие примеры: shoppen bis der Arzt kommt - разг. ‘шопиться до потери пульса/сознания’, latte sein - ‘без разницы’, ‘по барабану’, ‘фиолетово’, ‘быть (кому-л.) абсолютно неважным, безразличным’. Очевидно, что фразеологизм (jmdm.) latte sein образован от существительного Latte Macchiato по аналогии с уже существующим немецким фразеологизмом (jmdm.) wurst/wurscht sein - ‘быть по барабану', имеющим то же значение.

Особую эмоциональную выразительность придают разговорной речи различные междометия и частицы: $u p s-$ разг. 'ой', 'упс', восклицание, сопровождающее нечто неожиданное, особенно мелкую неприятность, оплошность. В неожиданных ситуациях от немцев всё чаще можно услышать не привычное восклицание Hoppla!, а новое Ups!

Использование заимствованной лексики в разговорной речи может быть следствием не одной, а сразу нескольких взаимодействующих причин, что отражает следующая диаграмма.

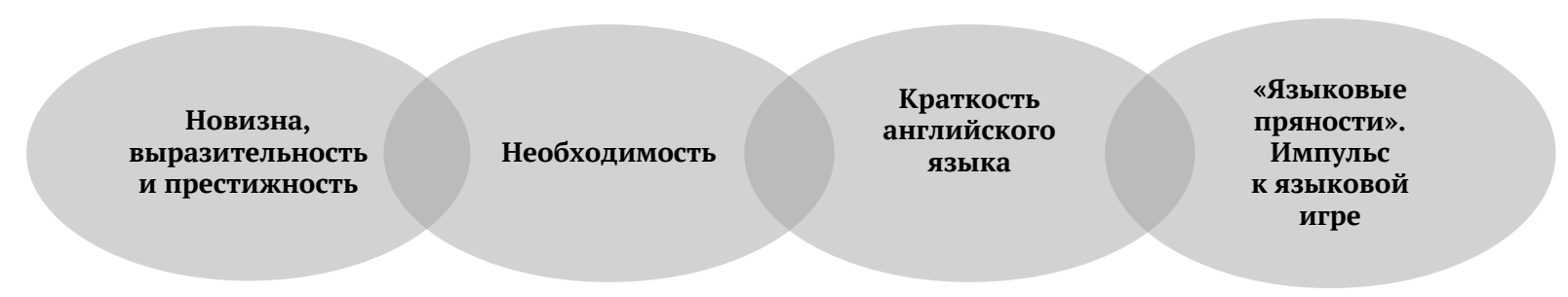

Диаграмма 2. Причины использования коллоквиализмов-заимствований в разговорной речи

\section{Диафазический (стилистический) аспект описания новых коллоквиализмов-заимствований}

Использование разговорной речи в неформальном общении позволяет рассматривать разговорный стиль как особый функциональный стиль речи, которому присущи экспрессивность, эмоциональность и образность. Новые коллоквиализмы-заимствования являются, как правило, образными лексическими единицами. Так, англицизмом Soap - ‘мыло’ называют мыльную оперу, мыльный сериал; англицизм hopping - 'прыгание, скакание’ в составе сложных слов с первым немецким или также англоязычным компонентом способствует созданию яркого, наглядного образа: Ӓrztehopping - 'частое посещение пациентом различных врачей-специалистов, стимулированное наличием медицинской страховки', Beziehungshopping - 'частая смена отношений, Jobhopping 'частая смена работы'. Производный от слова Rock глагол rocken имеет метафорическое значение 'зажечь, покорить, потрясти кого-л.', так как рок-музыка обладает большой захватывающей энергией.

Глагол pampern, образованный от слова Pampers, торговой марки компании Procter \& Gamble, выпускающей под этим брендом подгузники, заимствован немецким языком в значении 'возиться, нянчиться с кемл./чем-л.' и несет негативную оценку. Намекая на детские подгузники фирмы «Памперс», говорящие выражают неодобрительное отношение к чрезмерной поддержке кого-л., неоправданному содействию чему-л. Поэтому глагол снабжен в Словаре неологизмов пометой разг.-насмешл. [19].

Некоторые разговорно-окрашенные заимствования являются шутливыми словами. Того, кто любит проводить время перед телевизором и ест при этом сладости, выпечку и т.п., называют в неофициальной обстановке шутливо Couchpotato - ‘лежебока', ‘диванный овош/лентяй, ‘кушеточная картошка'. Молоко, которое сохраняется свежим в течение месяца благодаря определенным технологиям обработки, называется $E S L$ Milch - 'долгоиграющее молоко'. Это сложное слово-гибрид, которое состоит из аббревиатуры ESL (сокр. От Extended Shelf Life - увеличенный срок хранения) и немецкого существительного Milch.

Чехол из материала цветов национального флага, обтягивающий тыльную часть боковых зеркал автомобиля, обозначается сложным словом Carbikini -разг. 'автоушко' (дословно «бикини для машины/автомобиля»). Объемная форма боковых зеркал автомобиля послужила основанием для использования слова Bikini в качестве основного слова номинации. Шутливость возникает благодаря метафорическому переосмыслению слова Bikini. Англицизм Car является лишь более кратким и удобным словом для образования композита.

Supernanny - 'суперняня', 'человек, чаще женщина, компетентный в решении социально-педагогических проблем’. Это слово также является шутливым. В немецком языке обозначение Supernanny, пришедшее из английского языка, приобрело расширенное значение. “Die Super Nanny” - название развлекательной телепередачи, оригинальный формат которой был создан в Великобритании. Сюжет передачи состоит в следующем: в семью, где у родителей есть проблемы с воспитанием детей, приезжает детский и семейный психолог - суперняня, которая после наблюдения за семьей предлагает способы решения проблем воспитания. В немецкой версии телепередачи, идущей с 2004 г. на телеканале RTL, в роли суперняни выступает дипломированный педагог Катарина Зальфранк (Katharina Saalfrank) [10]. 
Оба слова не отмечены в Словаре неологизмов как разговорные. Однако шутливая окраска данных слов позволяет отнести их к коллоквиализмам, так как шутливые слова употребляются в непринуждённой обстановке для того, чтобы расположить собеседника к раскованному, доверительному общению.

Слово Greenwashing - 'гринвошинг', 'попытка компании повысить свой престиж путем рекламы экологичных продуктов, преуменьшив серьезность негативного влияния собственной деятельности на окружающую среду’ имеет помету насмешливое. Как и рассмотренные выше шутливые слова Carbikini и Supernanny, это слово авторы словаря не считают коллоквиализмом. Однако и в этом случае употребление слова предполагает атмосферу свободного, раскованного общения.

Рассмотрев диафазический аспект новой разговорной лексики, мы разделяем точку зрения Л. Б. Копчук, согласно которой характер обиходно-разговорного языка определяется не одним, а одновременно несколькими - региональными, социальными и ситуационными - факторами, связанными друг с другом и дополняющими друг друга [4].

\section{Диастратический (социальный) аспект описания новых коллоквиализмов-заимствований}

Коллоквиализмы как лексические единицы общеразговорного языка могут быть противопоставлены жаргону. Под жаргоном принято понимать социолект, речь какой-либо социальной или иной объединенной общими интересами группы людей. Коллоквиализмы иногда рассматривают как лексику, менее респектабельную, чем стандартная, но более респектабельную, чем жаргон, или сленг.

Отличительными чертами жаргонизмов в отличие от коллоквиализмов являются их меньшая частота употребления, более узкая сфера распространения, недостаточная понятность, более яркая эмоциональная окраска и экспрессивность. Обычно различают общий и специальный жаргон. Специальные жаргонизмы, или сленгизмы, мы рассматриваем как лексику, которой пользуются люди, связанные одной профессией или общностью интересов.

Среди неологизмов с пометой жаргон можно обнаружить жаргонизмы узкой сферы распространения, как, например, жаргонизм сферы экономики (Wirtschaftsjargon) Cashcow, die - 'денежная/дойная корова', 'продукт, который приносит доход’. Три новых заимствования являются жаргонизмами, которые употребляются в языке рекламы (Werbesprache), однако толковый словарь ДУДЕН не помечает их как жаргонизмы: Best Ager, der - ‘бестейджер/бестэиджер’, Docutainment, das - ‘докьютейнмент', Give-away, das - ‘бизнес-подарок', 'рекламный подарок/сувенир’. Жаргонизм Loha, der/die - ‘тот, кто ориентирован на сбережение природных ресурсов’ не зафиксирован в словаре Дуден как жаргонизм определенной профессиональной сферы [17].

Можно выделить жаргонизмы, которые переходят из узкой сферы употребления в общий обиход, например: Bad Bank - 'плохой банк'. Первоначально словосочетание Bad Bank относилось к специальному жаргону банкиров и финансистов, но позже вошло в общее употребление. Несколько других жаргонизмов стали общеупотребительными словами. В словаре ДУДЕН они не содержат помет, например: Aftershowparty, die - 'вечеринка, организованная сразу после окончания развлекательного мероприятия для его участников’, Couchsurfing, das ‘коуч(-)сёрфинг', ‘бесплатный ночлег', Edutainment, das - 'развлекательное обучение’, Nerd, der - 'тот, кто одержим изучением какой-то специальности и уделяет ей много времени', Streetwear, die - 'повседневная одежда', Get-together, das - 'встреча без галстуков’, ‘неофициальная/неформальная встреча’ [Ibidem].

Таким образом, наблюдается переход жаргонизмов в разряд общеупотребительной лексики. Лексика людей, связанных одной профессией или общностью интересов, выходит за границы социолекта и распространяется среди всех носителей языка. Слова, которые были отмечены Словарем неологизмов как жаргонизмы, авторами толкового словаря рассматриваются как общеупотребительные.

Отдельную группу жаргонизмов составляет лексика молодежного жаргона (нем. Jugendsprache). Среди этой лексики зафиксированы заимствованные слова, например, глаголы chillen - 'чилить', 'релаксовать', dissen 'гнобить', 'опускать' (англ. to diss от disrespect) и гибридные слова, образованные от заимствованных слов с помощью немецких аффиксов или глагольных частиц, например, глагол abspacen - 'отключаться от реальности’, ‘быть в улёте’ (полукалька с английского глагола to space out). От глагола chillen с помощью немецкого суффикса -ig образуется прилагательное chillig - 'чилаутный. Глагол telen - 'рингать' - сокращенная форма глагола telefonieren - ‘звонить'. Среди существительных встречаются прямые заимствования из английского языка (Clubwear - 'клубный прикид’) и псевдоанглицизмы (DJane - ‘девушка-диджей’). Эмоциональность речи молодежи находит отражение в том, что из английского языка заимствуется также незнаменательная лексика, как частица уер, заменяющая в молодежном жаргоне немецкое $j a$.

Молодежный жаргон - более современная и модная лексика, чем общеупотребительные коллоквиализмы. Со временем, как отмечалось выше, жаргонизмы молодежного языка выходят за границы жаргона и начинают употребляться не только молодыми людьми, но и взрослыми. Так как жаргон недолговечен, одни жаргонизмы постоянно заменяются другими, новыми и более престижными, а бывшие некоторое время в употреблении молодежи жаргонизмы становятся общеразговорными коллоквиализмами.

Таким образом, граница между молодежными жаргонизмами и коллоквиализмами является нечеткой и размытой. На размытость границ между жаргонизмами, употребляемыми молодежью, и коллоквиализмами указывает то, что некоторые слова помечаются одними авторами словарей как слова молодежного жаргона, другими - как коллоквиализмы. 
Так, глагол dissen, согласно Словарю неологизмов, относится к молодежному жаргону, однако на сайте Википедии находим информацию о том, что это разговорное слово [14], которое пришло в немецкий язык как жаргонизм хип-хоп-культуры, субкультуры, созданной в странах Карибского бассейна. Поэтому глагол dissen может также рассматриваться как слово, которое относится к определенной молодежной субкультуре. B словарях DWDS и ДУДЕН глагол dissen помечен как жаргонизм, прежде всего, из языка рэперов [17; 18]. В словаре Wiktionary глагол dissen снабжен пометами жаргон и разговорно небрежное [15].

Особый пласт лексики в немецком языке образуют слова с пометой субкультурное (Szenesprache). Анализ этой лексики показывает, что она близка как молодежному жаргону, так и коллоквиализмам. Так, к субкультурной лексике относятся прямые заимствования из английского языка. Это обозначения лиц: Thirtysomething 'человек в возрасте между тридцатью и сорока годами' и Twentysomething - 'человек в возрасте между двадцатью и тридцатью годами', Bling - ‘незнакомый человек, которому назначено свидание', Date - 'тот, кому назначено свидание для дальнейшего развития взаимных отношений и Blind Date - в значении 'незнакомый человек, которому назначено свидание'. Существительное Dating имеет значение 'свидание двух людей для дальнейшего развития взаимных отношении; череда таких свиданий, глагол daten - 'условиться о свидании'; ‘встречаться с кем-л. для дальнейшего развития взаимных отношений.

B словаре DWDS лексические единицы Date и Blind Date в значении 'встреча, назначенное время встречи' помечены как коллоквиализмы [18]. Таким образом, в основном значении эти слова являются общеупотребительными разговорными, а в метонимическом значении, обозначающем тех, кому назначено свидание, они ограничены в употреблении сферой субкультуры.

Субкультура находит выражение в особой лексике: Poetry Slam - ‘поэтический слэм’ и Slam Poetry - ‘литературные произведения собственного сочинения’; ‘литературный жанр, объединяющий такие произведения’. Словарь DUDEN, однако, относит эти лексические единицы к лексике стандартного языка [17].

Субкультурно маркированы заимствованные англицизмы: Don't - ‘запрет, табу', часто в сочетании Dos und Don'ts - 'рекомендации, что нужно делать и что нельзя’ [19]. В словаре ДУДЕН это словосочетание также помечается как жаргонизм. Слово Must-have, das имеет значение 'то, что должен иметь каждый, чтобы быть модным’. Словарь ДУДЕН не содержит помет для данного слова. Третье слово No-Go, das - ‘дурной тон’, ‘моветон’, 'не комильфо'. В словаре ДУДЕН оно сопровождается в одном значении пометой Wirtschaftsjargon - 'жаргонизм сферы экономики', в другом - разговорное [17].

Таким образом, лексика субкультур является наиболее нечетко отграниченной как от жаргонизмов и коллоквиализмов, так и от общеупотребительной лексики.

Что касается заимствованных жаргонизмов, включая молодежный жаргон и лексику субкультур, в целом обращает на себя внимание то, что они почти без исключения заимствованы из английского языка. В отличие от коллоквиализмов, заимствованных ранее из французского и латинского/греческого языков, жаргонизмыанглицизмы являются современными заимствованиями и не ассимилировались в немецком языке. Можно сделать вывод, что через прямое заимствование английский язык пополняет прежде всего жаргонную лексику и в меньшей степени - коллоквиальную, которая формируется в основном посредством словообразования, включающего заимствованные элементы.

\section{Тематический аспект описания новых коллоквиализмов-заимствований: коллоквиализмы-заимствования эпохи пандемии коронавируса}

В словаре лексики пандемии [13] зафиксировано всего десять коллоквиализмов (общее количество слов - 305). Из них три являются исконно немецкими словами, остальные - это главным образом коллоквиализмы, образованные при помощи заимствованных элементов.

Разговорное слово для обозначения коронавируса в немецком языке - Corona - корона, усеченная форма сложного слова Coronavirus.

Слово Balkonien (возможный эквивалент в русском языке - слово ‘балкония’, ‘собственный балкон или собственная квартира как место, в котором проводят отпуск по причине отказа от путешествий’) - дериват, образованный от заимствованного слова Balkon - балкон (франц. balcon, итал. balcone) по аналогии с названиями стран, оканчивающимися на -ien, например: Albanien, Bulgarien, Italien, Spanien и др. Слово употребляется шутливо, иногда иронично.

Пять слов представляют собой гибридные образования в немецком языке, по форме композиты, состоящие из слов, заимствованных из разных языков: англ. + лат./греч. Babyelefant, der - 'слоненок' (англ. baby

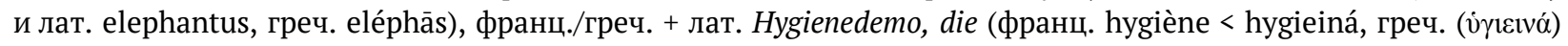
'здоровый образ жизни, здоровье' < hygieinós греч. (ن̛łıเvós) ‘здоровый’ и лат. dēmōnstrātiō).

Слово Babyelefant 'слоненок' употребляется шутливо в переносном значении 'обязательное минимальное расстояние в один метр между людьми для защиты от заражения коронавирусом в Австрии’, где стали выпускать слонят из пенополистирола, чтобы напоминать о необходимой минимальной дистанции и измерять длину слонятами. Babyelefant стало словом 2020 года в Австрии, получив почти 50\% голосов членов жюри и намного опередив слово Corona. Таким образом, выбрав шутливый коллоквиализм Babyelefant в качестве слова года, австрийцы показали, что обладают чувством юмора. Они проявили креативность в отличие от серьезных немцев, для которых словом года стало слово Corona-Pandemie. 
Коллоквиализмы Balkonien и Babyelefant эмоционально окрашены, они выражают отношение к называемым явлениям, что характерно для повседневной речи.

Другие гибридные образования Coronasünder, der - 'ковидный грешник' и Coronasünderin, die - 'ковидная грешница’ - композиты, состоящие из заимствованного слова и немецкого (лат. Corona + нем. Sünder/Sünderin 'грешник/грешница'). Так называют тех, кто во время пандемии, вызванной коронавирусом, не соблюдает законы и распоряжения. Композит Maskenmuffel, der - 'тот, кто отказывается носить маску' состоит из заимствованного слова и немецкого (франц. таsque, итал. maschera + нем. Muffel).

Одно слово - глагол hamstern - ‘хомячить', ‘делать запасы, как хомяк' имеет помету salopp (небрежно), которая близка помете разговорное. Глагол hamstern образован от существительного Hamster - ‘хомяк', способ его образования - конверсия. На первый взгляд, слово Hamster кажется исконно немецким, но, обратившись к словарю, можно увидеть, что это слово заимствовано из русского языка (chomják). Глагол hamstern стал употребляться в немецком языке после Первой мировой войны и получил снова распространение в эпоху пандемии коронавируса.

Как показывают примеры, коллоквиализмы - редкое явление в лексике пандемии коронавируса. Прямых заимствований практически нет. Бо́льшая часть рассмотренных слов - это результат гибридного словообразования в немецком языке. Речь идет о давно употребляющихся в немецком языке заимствованных словах, которые используются в словосложении и не воспринимаются большинством носителей языка как заимствованные.

\section{Заключение}

Таким образом, можно сделать вывод, что коллоквиализмы-заимствования в немецкой разговорной речи представляют собой частично ассимилированную лексику, которая была заимствована из французского, латинского и греческого языков. В современном немецком языке речь идёт преимущественно о заимствованиях из английского языка. Такого рода заимствования служат для возбуждения интереса и привлечения внимания: они более выразительны и престижны, чем немецкие слова, или соответствующие понятия отсутствуют в немецком языке. Заимствования являются выражением человеческой потребности в том, чтобы будничным и привычным предметам и явлениям дать необычные и лаконичные названия.

Кроме того, описание коллоквиализмов-заимствований в диафазическом, диастратическом и тематическом аспектах позволило сделать следующие выводы.

1. Большая часть коллоквиализмов - это привычные, простые, понятные слова, отвечающие норме повседневной коммуникации. Поэтому среди них находит место главным образом ассимилированная лексика. Новые коллоквиализмы-заимствования отличаются экспрессивностью, эмоциональностью и образностью. Многие из них имеют шутливую окраску, с их помощью в повседневной речи достигается комический эффект.

2. Коллоквиализмы как лексические единицы общеразговорного языка противопоставлены жаргону. Со временем жаргонизмы переходят в разряд общеразговорной лексики. Граница между молодежными жаргонизмами и коллоквиализмами является нечеткой и размытой: бывшие некоторое время в употреблении молодежи жаргонизмы становятся коллоквиализмами. Лексика субкультур является наиболее нечетко отграниченной как от жаргонизмов и коллоквиализмов, так и от общеупотребительной лексики.

3. Современные заимствованные жаргонизмы, включая молодежный жаргон и лексику субкультур, почти без исключения являются не ассимилированными в немецком языке англицизмами. Англицизмы пополняют прежде всего жаргонную лексику и лексику субкультур и в меньшей степени коллоквиальную, которая формируется в основном посредством гибридного словообразования с автохтонными и заимствованными элементами.

4. В лексике пандемии коронавируса заимствованные коллоквиализмы - редкое явление. Заимствованные слова используются в словосложении в качестве словообразовательных элементов слов-гибридов.

Перспективы дальнейшего исследования проблемы мы видим в изучении сопоставительного аспекта коллоквиализмов-заимствований в немецком и русском языках.

\section{Источники | References}

1. Девкин В. Д. Немецкая лексикография. М.: Высшая школа, 2005. 670 с.

2. Девкин В. Д. Немецкая разговорная речь: синтаксис и лексика. М.: Международные отношения, 1979. 257 с.

3. Девкин В. Д. Немецко-русский словарь разговорной лексики. М.: Русский язык, 1994. 768 с.

4. Копчук Л. Б. Статус обиходно-разговорного языка в системе немецких социолектов // Материалы конференции, посвященной 90-летию со дня рождения члена-корреспондента РАН А. Н. Десницкой. СПб.: Наука, 2002. С. 102-108.

5. Коротких Ю. Г. Коллоквиализмы-заимствования в современном немецком языке: дисс. ... к. филол. н. М., 1974. 347 с.

6. Нефедова Л. А. Иноязычная лексика современного немецкого языка (аспекты культурной интеграции): монография. М.: МПГУ, 2018. 184 с.

7. Нефедова Л. А. Явление девиации в лексике современного немецкого языка: дисс. ... д. филол. н. М., 2003. 365 с.

8. Никитина Е. А. Наречия-коллоквиализмы современного немецкого языка: дисс. ... к. филол. н. М., 1999. 235 с. 
9. Собянина В. А. Взаимодействие специальной и обиходной лексики в современном немецком языке: дисс. ... д. филол. н. М., 2005. 424 с.

10. Штеффенс Д., Никитина О. А. Немецко-русский словарь неологизмов. Новая лексика в немецком языке 1991-2010. Мангейм: Институт немецкого языка, 2016. Т. 1-2. 598 с.

11. Ammon U. Die deutsche Sprache in Deutschland, Österreich und der Schweiz. Das Problem der nationalen Varietäten. Berlin - N. Y.: De Gruyter, 1995. 575 S.

12. Best K.-H. Zur Entwicklung des Wortschatzes der deutschen Umgangssprache // Glottometrics. 2010. № 20. S. 34-37.

13. DWDS-Themenglossar zur COVID-19-Pandemie [Электронный ресурc]. URL: https://www.dwds.de/themenglossar/ Corona (дата обращения: 07.07.2021).

14. https://de.wikipedia.org/wiki/Dissen_(Umgangssprache) (дата обращения: 07.07.2021).

15. https://de.wiktionary.org/wiki/Wiktionary (дата обращения: 07.07.2021).

16. https://jannisandroutsopoulos.files.wordpress.com/2010/11/7-entlehnung.pdf (дата обращения: 07.07.2021).

17. https://www.duden.de/(дата обращения: 07.07.2021).

18. https://www.dwds.de/wb/Lockdown (дата обращения: 07.07.2021).

19. Neologismenwörterbuch [Электронный ресурc]. URL: https://www.owid.de/docs/neo/start.jsp (дата обращения: 07.07.2021)

20. Ortner H. Wortschatz der Mode: das Vokabular der Modebeiträge in deutschen Modezeitschriften. Düsseldorf: Pädagogischer Verlag Schwann (Sprache der Gegenwart 52), 1981. 324 S.

\section{Информация об авторах | Author information}

RU Белякова Олеся Павловна ${ }^{1}$

Нефедова Любовь Аркадьевна ${ }^{2}$, д. филол. н., проф.

1,2 Московский педагогический государственный университет

EN Belyakova Olesya Pavlovna ${ }^{1}$

Nefedova Lyubov Arkadyevna ${ }^{2}$, Dr

${ }^{1,2}$ Moscow Pedagogical State University

${ }^{1}$ op.belyakova@mpgu.su, ${ }^{2}$ la.nefedova@mpgu.su

\section{Информация о статье | About this article}

Дата поступления рукописи (received): 13.07.2021; опубликовано (published): 15.09.2021.

Ключевые слова (keywords): заимствование; коллоквиализм; коллоквиализация языка; разговорная речь; немецкий язык; borrowing; colloquialism; colloqualization of language; colloquial speech; German language. 